\title{
Caronae
}

\section{ridesharing and first steps into commuting opportunitie of academic exchange}

\author{
Luisa da Cunha Teixeira ${ }^{1}$, Rodrigo Cury Paraizo $^{2}$ \\ ${ }^{1,2}$ LAURD-PROURB-FAU-UFRJ \\ ${ }^{1}$ luisadacunhateixeira@gmail.com²rparaizo@gmail.com
}

Location-based mobile applications have been a rising theme for academics in the field of urbanism and in urban and transportation, because of the potential of transformation they might bring to the urban landscape (De Souza e Silva, 2013). One of the possibilities we study here is to observe social encounters fostered by commuting rides. In this paper, we try to examine the practice from the broad perspective of estimating the environmental benefits, in a context where digital information technology is wielded to address problems old and new (Townsend, 2014). This paper aims to analyze the potential of transformations that new ICTS bring to urban mobility, using as case study the official ridesharing system of the Federal University of Rio de Janeiro, the Caronae project. The system was developed focusing on the reduction of the number of motorized trips to the University, as well as the amount of $\mathrm{CO} 2$ generated by them. Here we analyze the dynamics of ridesharing, using the system data, and also try to observe the role it may play towards the promotion of integration in the UFRJ community.

Keywords: mobile apps, urban mobility, ridesharing, caronae ufrj

\section{INTRODUCTION}

Urban mobility is a central issue for big cities today. Everywhere the impacts of urban planning directed at the private owned cars is felt, and even harder in places such as Brazil with relatively small investment in public transportation. The results accumulated throughout the years have directly influenced the quality of life of citizens in urban centers. More frequent - and lengthier - traffic congestions have altered daily commuting travel times. This, and an increase in the number of car accidents and air pollution rates, adds up to elevate daily stress in ur- ban settings. In Rio, as well as in other metropolis around the world, collective transportation is illplanned and frequently inefficient, with little intermodal connection, limited routes and overcrowded at peak times. Most cars used to commute travel as single-occupant vehicles, generating externalities like congestion and pollution. A relatively efficient and sustainable transportation option for addressing these concerns is ridesharing-the practice of sharing a car with other passengers, either for free or by sharing travel expenses.

Information technology has long been used to 
help urban mobility, and the recent developments in GPS and mobile technologies has been rapidly adopted, and fostered a whole ecology of urban mobility applications. Indeed, it can be argued that terms like "smart cities" are heavily connected to urban mobility solutions, and that they are among the first types of applications people think about when referring to such terms. Apart from mobility in itself - hailing a cab, informing where is and when will arrive the next bus, for instance -, many applications that use geo-referenced information, such as taxi apps, Uber, public transport monitoring applications, bicycle and car sharing applications, generate a plethora of data on urban dynamics. Most of the time, this data is used to further improve urban transportation systems, working as a feedback system. However, there are many social and cultural patterns embedded in such data that can be used to interpret and describe many urban phenomena. One of the first and most widely known examples is "Real Time Rome", teh MIT Media Lab project developed as part of the 10th International Architecture Exhibition in Venice to visualize different location and movement patterns of cellphone users in the Italian capital city, identifying which monuments concentrated most tourists, for instance (Calabrese and Ratti, 2006; Calabrese et al, 2011). In Spain, BorgeHolthoefer et al (2011) analyzed popularity and social network distribution of tweets about the protests in May 15th of the same year. Another example is how Netto et al (2018) use Twitter locational metadata and demographic data to potential encounters occurring among people of different economic status in Rio de Janeiro.

This paper aims to present the analysis of current data from the official ridesharing application of the Federal University of Rio de Janeiro. The research goal is to identify whether ridesharing does provide opportunities of academic exchange inside the University, among different courses and among different groups of people. In the process, we also try to observe the larger picture of ridesharing behaviour in our University, as well as indicate possible further developments of the ridesharing system itself, especially in its administrative interface.

The first part of the paper presents the Caronae project, since its creation to operation and future developments. The project intends to safely connect people who attend the campus of the University and have the same daily routes, based on a mobile application and designated meeting points throughout the campi. We analyze the different aspects of the project, within a theoretical framework about the use and possibilities of the new ICT and location-based technologies for the cities, to understand its insertion in the urban context.

The second part of the paper compares Caronaê to similar apps, examining how each app deals with urban mobility in general. We address a previous stage of the research that presents the classification of examples of digital platforms in four main categories according to the type of function they carry out on urban mobility. This allows us to recognize the context in which the project to be analyzed is inserted

In the third part, the Caronaê database is examined, in order to find its demographics and to identify possible patterns, especially concerning diversity chance encounters of its users. First, we focused on the dynamics of urban mobility and the effects of ride sharing on the university's round trips, that is, how it helps to mitigate the effects of private car oriented transportation. As a complementary analysis, we also sought to reflect on how the system creates networks of interactions among users, strengthening community ties among the institution and promoting a greater exchange between different profiles of users and categories of UFRJ.

\section{CARONAÊ: A RIDESHARING SYSTEM AT UFRJ}

The Caronaê UFRJ project is the official ridesharing system of the Federal University of Rio de Janeiro. The system consists of a mobile application restricted to the academic community (students, professors and administrative technicians) combined with sig- 
Figure 1

physical displays of official meeting points inside the University

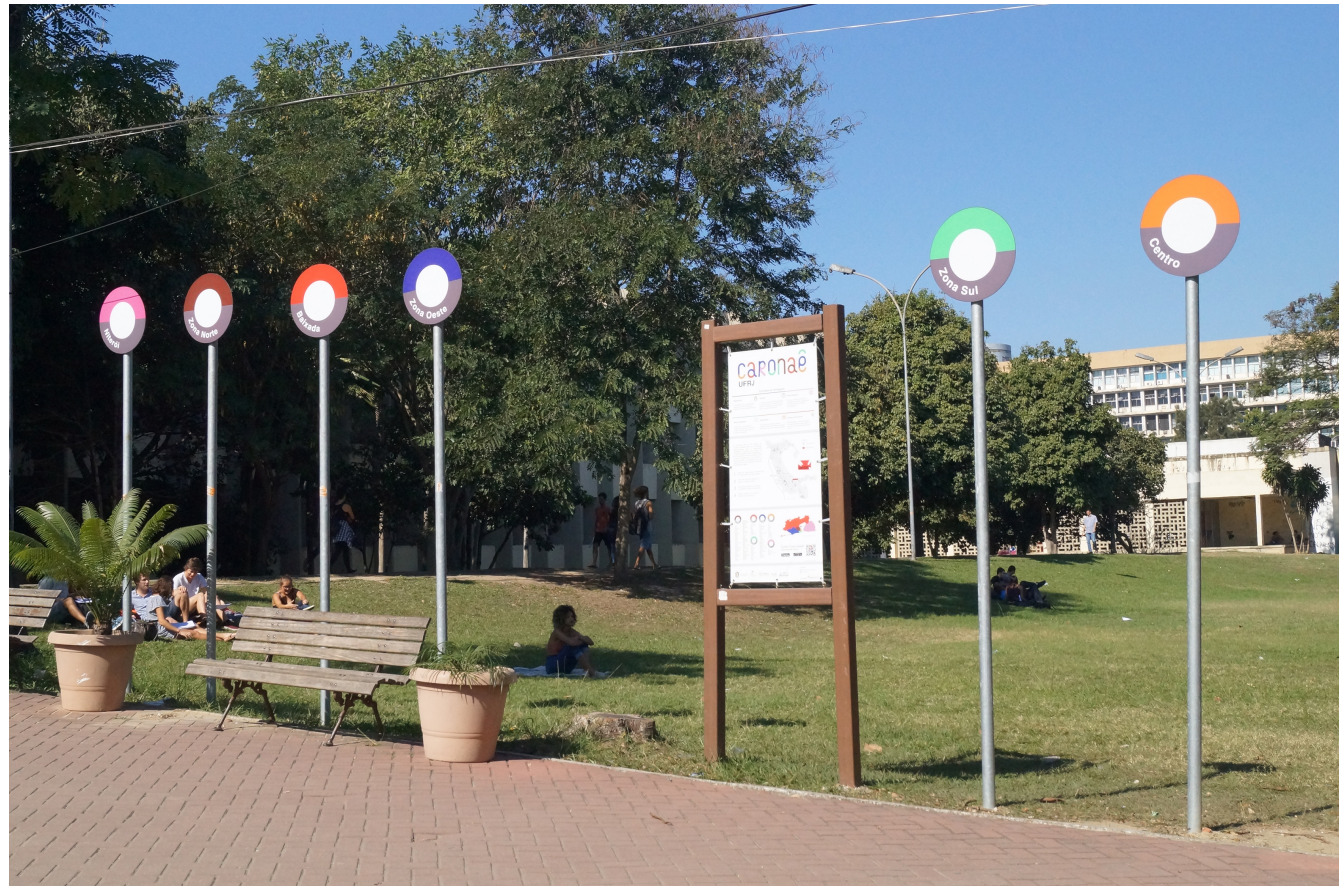

naled ridesharing meeting points near the buildings of different UFRJ campi. The system allows the sharing of car trips, optimizing the daily commuting to the University.

\section{Concept}

Initially, the idea of Caronaê came from a group of UFRJ students, as a proposal for the "Sustainable Solutions" competition organized by the UFRJ "Green Fund" in August 2014. The project was awarded in the category "Mobility" and began to be implemented in 2015.

The Caronaê system seeks to securely connect people who attend the campi of the Federal University of Rio de Janeiro and carry out daily commutes in common. It started with the main campus, at llha do Governador, where access has always been an issue, due to scarce options of collective mass trans- portation - nowadays, only regular buses and BRT vehicles; there is no access by subway or train, or even maritime access (since it is an island). Therefore, many people opt for the use of private cars, which creates enormous problems of traffic, especially at peak times. Also those private cars usually transport only their drivers, an occupancy rate below that supported by the vehicle. If historically ridesharing has always been an option, to offer a ride to (or accept one from) strangers is a practice that has noticeably diminished over the years, mainly due to safety issues.

In this sense, the project identified a constant and growing demand of the UFRJ community and sought, through the resources and options offered by the technology, to unify all car offers in a single platform, aiming to facilitate and expand the ridesharing dynamics, while somewhat ensuring that partici- 
pants were verified members of the UFRJ community, thus potentially improving the safety of the practice.

The name Caronaê derives from a contraction of the Brazilian word "carona", that means ride, and the interjection "aê", characteristic of the way of speaking in Rio de Janeiro, indicating an appeal or call, and its initial inspiration came from the use of the expression "Vai uma carona aê? ", that means "Do you want a ride?".

\section{Implementation}

Since its idealization, the project has been divided into three parts: the virtual framework, consisting of the software and the underlying database; the physical framework, consisting of the physical displays of official meeting points inside the University; and the cultural framework, based on the constant need to advertise the system and its benefits to its potential users, in order to expand among older students, teachers and other servants, as well as to attract the new users that enter the University each semester.

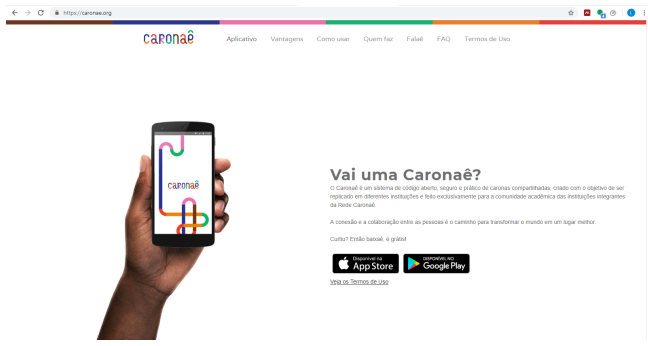

The virtual scope is the basis of the system, consisting of a mobile application for Android and iOS systems, which concentrates the offers of rides and the database that lists the system information on the server. The system basically functions as a digital platform where each driver can offer the rides, and other users can request them while browsing through a list of offered rides. Users who wish to offer rides can publish them by informing the following information: 1) If it is arriving (inbound) or leaving (outbound) UFRJ ; 2) Origin; 3) Reference point; 4) Route; 5) Destination; 6) Date and time; 7) Spots available It is also possible to inform whether a ride is routinely offered on a weekly basis or if it is a single offer, and to include additional notes like: "no smoking and no pets" or "contribution of 4,00 reais" .

Offered rides are available to all users in the "All" tab of the application, which provides filters by zone, neighborhood and campi. The process of searching and requesting a ride is done by accessing this list. When finding a ride, the user can choose it, see more details and, if he or she wishes, make the request to share the trip. The driver who offered the ride receives the request and can evaluate whether or not he accepts, accessing more information on the profile of the rider. If the evaluation is positive, the driver accepts the request and the rider receives a warning. From there the two users are connected through a private chat within the app and some additional information about the ride is made available, such as: model, car plate and the contact information of all participants. In the "My trips" tab, all the offered, pending and active rides of a user are also related. Drivers, in addition, can see their past and pending offers. Rides can be "pending", that is, with requests waiting to be accepted, or "active", with at least one accepted request.

Taking into account the safety of the users, the Caronaê is based on the premise of an access system exclusive for the community of the University, a differential that guarantees greater safety for users and hitchhiking practitioners. In order to realize this premise and ensure that only active members of the University (student, professor or technicaladministrative) have access to the service, the system connects to the UFRJ registration database, through the support of the Information and Communication Technology team (ICT-UFRJ). Access to the application is through the CPF number and the UFRJ Intranet password. This procedure guarantees the authentication of the user's profile at the first access and associating some official data with the user profile that cannot be changed: name, category UFRJ and, in case of students, the course in which they are enrolled.
Figure 2

Caronaê's official website 
Figure 3

Screenshots of the Caronaê app
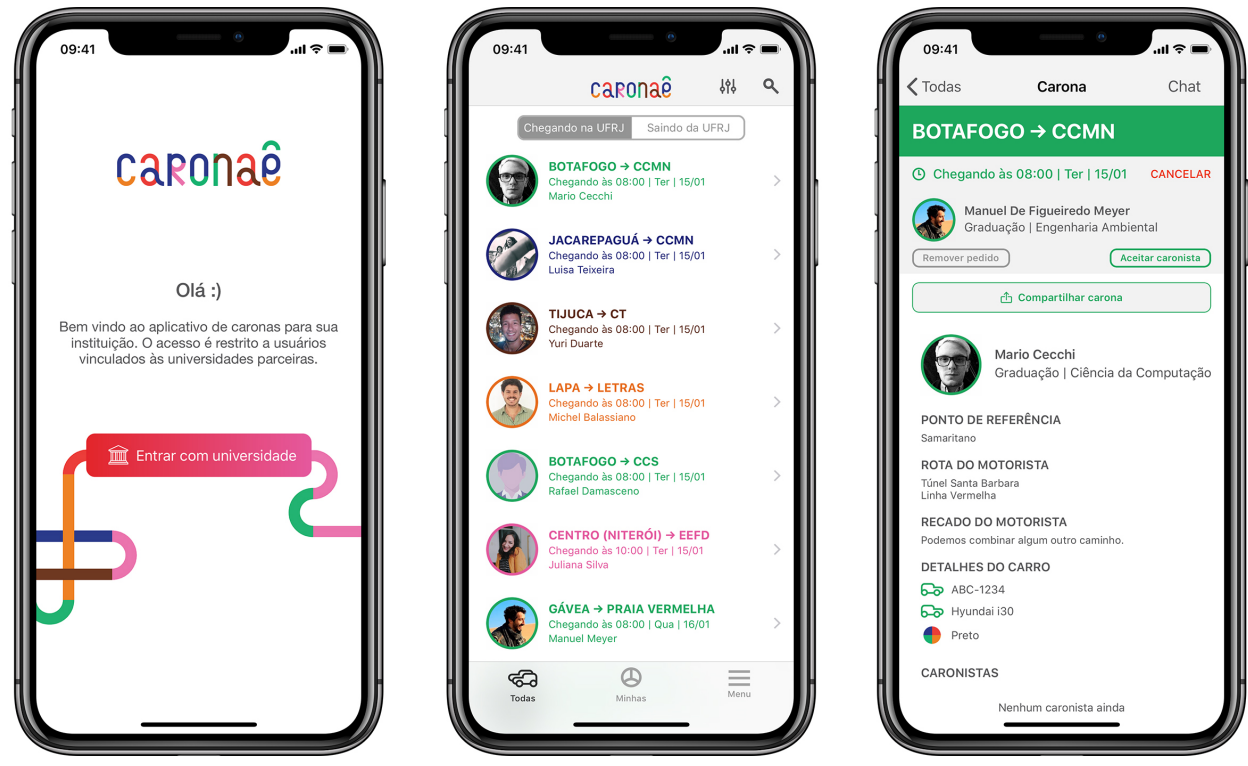

\section{Use of the system}

The system was launched in April 2016 and since then about 16 thousand users have registered and more than 50,000 rides were created. All the interactions performed within the system, since it is being active, are recorded in the database, as we will see in the third section.

Despite the difficulties along the way, the project had the support of the University campus manager after its implementation and in January 2017 was accepted as an official Extension Project, consolidating its institutionalization. The extension project is based on the expansion, through the replication of the system in other institutions, especially other public universities and is directly connected to the NIDES (Interdisciplinary Center for Social Development). This process was thought to be carried out by opening the system source code, that is, transforming it into an open source system, allowing its replication in other interested institutions in a much simpler and more collaborative way. From this model it was intended to create a connected network of contributions to the same source code, initially based at UFRJ.

Thus, in the middle of 2017, Caronaê was made available as an organization in the open source GitHub platform, following the GNU General Public License v3.0, which allows the total reproduction of the system, including for commercial and lucrative purposes, as long as the same is kept open, allowing any enhancements and new functionality to be added back to the original code. With the open source code the entire community is free to run, study, examine and track Caronaê's source code. All these modifications can be submitted to the project repository so that the changes, after being evaluated and incorporated by the team, are made available to all users of the Caronaê network.

It should be noted that data shows that the use of the platform has been decreasing over time, which the Caronaê team attributes to a few factors: technical problems at the beginning of the project; the lack of appropriate institutional support (funding, peo- 
ple and even the unclear institutional insertion of the project); the lack of continuous advertisement focused on new students; and the competition with other platforms, both specialist and non-specialist. Most of the rides in the dataset were recorded from April, 2016 to December, 2016, with a minor resurgence from March, 2017 to May, 2017.

\section{PLATFORMS FOR URBAN MOBILITY}

Caronaê is only one of the many alternatives that seek to improve urban mobility through information technology. Mobility in the context of this article means the physical displacement in the urban environment. Amar $(2016$, p. 13) states that information has become an essential component of transportation systems, and mobile technologies only enhance this role (Townsend, 2014, pos. 17). Indeed, it can be argued that the whole concept of "smart cities" (and, in a lesser measure, its more critical counterpart, "smart urbanism") arises from mobility-related applications in its early days, and its development is greatly enhanced by the ubiquity of cellphones and their embedded GPS capabilities.

There is a wide range of mobility services offered or improved by mobile apps. In a previous work (Teixeira and Paraizo, 2018), we examined different apps for iOS and Android devices in order to understand how each one dealt with urban mobility and how they could be grouped. based upon some categories, such as ownership of the vehicle, multi or single modality, and if there is (and how it is done when present) sharing of costs and rides, in order to understand the benefits of each platform in terms of environmental and social issues. The idea was to contextualize the project in relation to other digital platforms for transportation and to understand some of the ways that they could affect urban mobility, whether they could help induce a more sustainable urban development and also how could they affect social networks and encounters.

We perceived four main categories (each one with their own subdivisions): 1) mobility orientation, that is, apps that help users to navigate around the urban environment, such as Google Maps, Waze and the French RATP platform, which can be uni or multimodal; 2) on-demand transportation, or e-hailing, such as Uber, Lyft and 99, that essentially provide taxi or taxi-like services managed by a computer server; 3) vehicle sharing, that provides a digital interface to rent vehicles usually for daily, short trips, such as Velib and BikeRio, for bicycles, and AutoLib and Car2Go, for cars; and finally 4) ride sharing, the category where Caronaê is included, as well as BlaBlaCar and Zimride, which deals with the offer of empty spots in a vehicle for a given trip, improving the occupancy of the vehicle.

This last category is especially important by number of reasons when considering both sustainability and the possibility of exchanges. First, improving ride sharing, digitally or not, works towards the rationalization of vehicle use, according to the concept of Mobility Management (Balassiano et al., 2005), which is pivotal in the case of cars: studies show that the mean occupancy rate of private cars traveling in Brazilian urban environments is around 1,4 (Cet-SP, 2011). This translates in relatively big vehicles occupying large chunks of streets (and ultimately public space) to transport a single person most of the time. If the other person - or persons - in the vehicle are also car owners, this means one or more cars are left out of the equation for that trip, which also helps reduce fuel use and carbon emissions. In fact, in a previous work (Teixeira et al., 2018, p. 300), it has been established that this happened 908 times since the system was online, and an estimated saving in $\mathrm{CO} 2$ emissions of about $2982 \mathrm{~kg}$.

E-hailing (as regular taxi services), on the other hand, although works with improved occupancy rates, is indeed mostly transporting a single person, as the driver will still be riding the vehicle after the trip. Sharing a ride, however, also means that more than one person is going to be in the same closed environment for a few minutes, or even an hour, increasing chances of conversation among riders - as many than one taxi user can attest. It is very likely that ride sharing services that provide users with a 
common background, as is the case of Caronaê, will very likely induce conversations departing from this background. Also, as Caronaê deals with a daily commute of a closed (all participants know they belong to the same institution), large and relatively heterogeneous public (comparing, for instance, with an office building), the social exchanges may play an interesting role in spreading academic ideas and randomly connecting people. Even if in this stage of research it is not possible to confirm the actual social exchange, the examination of the database should provide some preliminary indication of how it could be happening.

\section{THE CARONAÊ DATABASE}

In this section, we examine Caronaê's database of rides and users in order to understand the profile of those involved, the distribution of rides along time and space and what kind of social encounters the system favors. As a digital platform, Caronaê has a database where all the information and system interactions are registered. We observe the data generated by the activity of the system to understand the dynamics of the rides in the UFRJ context, their space-time distribution and the social profile of the users, looking at it from both a broader perspective of environmental and climatic issues, highlighting how rides can be an alternative to reduce the number of trips in private cars - or make them more efficient and from a more specific perspective of possibly fostering the encounters and exchanges inside an academic community.

The Caronaê database is an object-relational database, accessed by PostgreSQL, an open-source object-relational database management system. The queries are done through the SQL, Structured Query Language, extracting various information from crossing database records. The majority of analysis here presented was performed by exporting SQL results in CSV files and importing then into Excel for processing.

We can separate the information obtained from the Caronaê dataset into two basic categories: users and rides. The main data about the users comes from the app login process using the UFRJ login info. As explained in the first section, this authentication, in addition to ensuring that the user is an active member of the academic community, also links some user profile data, which cannot be altered by the user in the app, in order to guarantee the authenticity of the profiles and, consequently, raising the security of system users. It consists of name, category UFRJ, and course (in case of a student user). Other information is provided by the user to complete the registration in the application: email, contact phone and neighborhood of origin. If the user is a driver, he must also inform some car data: model, license plate and color. This information only appears for the users who are in the same ride, to facilitate the contact and the meeting of all the participants.

The records of rides consist of the following fields: direction of the trip (outbound or inbound UFRJ), origin, destination, date, time, number of places, reference point and route. Working with the logic of the trip generating center (Redpgv, 2010), the Caronaê works for commutes related to a certain institution, in this case the UFRJ. That way, we have that, in inbound travel, the destination is always a hub of a UFRJ campus and the origin is always a neighborhood in one of the metropolitan area's regions. On the outbound or return trips the destination is one of the system designated areas in Rio.

\section{User profile}

As of the end of 2018, Caronaê had a total of 17,561 users. Of these users, 13,888 effectively completed the registration. Users who completed the registration are those who, after accessing and authenticating the profile via the Intranet, completed the additional contact information and added car information (when they want to register as trip offering drivers). For this study, we consider as active users in the system only the users with complete registration.

When analyzing the active users in the researched period, $94 \%$ of them are undergraduate or graduate students, divided into 9945 undergraduate 
users, 929 master courses students, 90 professional master courses students, 671 doctorate students and 55 specialization courses students. The total number of public servants, or University employees (teachers + administrative $\&$ technical staff) is 677 , only $6 \%$ of total active users - data extracted from the UFRJ 2020 Master Plan shows that they are actually $20 \%$ of the academic community. Despite the large number of complete registrations in the system, the number of registered users who completed at least one ride is much lower, indicating that not all users have actually used the application.

In a ride, users of the system are classified as riders or drivers. From the system point of view, every user is potentially a rider, able to browse rides and request ride offers; to be a driver, the user need to inform their willingness to offer rides and register their car information, as well as actively offer rides. Considering an optimal use of the system, with a good amount of rides offer, a driver may choose to take a ride instead of driving, leaving the car at home. In 2018,3094 users were drivers, which represents 22\% of total users with full registration. Among drivers, student users represent a total of approximately $90 \%$, leaving University employees as $10 \%$ of the total, a significant increase in relative participation in the system, although still less than the total number in the University. It is worth noticing that while the general car ownership ratio among students is around $1 / 5$, it increases to $1 / 3$ among students enrolled in Master courses.

The geographical distribution of the users by the city can be analyzed through the neighborhood that the user registers in its first registry. This data tells us about the main origin / destination of users, not actual rides. No matter how much the user offers rides coming from or going to points of the city others than the one informed in the user profile, the system so far is designed to record only that information. As it is, however, data still show us the general distribution of users across the territory. It allows us to know, for example, the neighborhoods with the most registered users: Tijuca, with 944, followed by Copaca- bana (590) and Niterói/Central Area (529) - Niteroi is a nearby city with a strong commuting relationship with Rio de Janeiro.

This geographical analysis of users in the city can also be made in relation to the rides registered in the system, revealing spatial aspects of the rideshare dynamics. The next section analyzes this and other aspects of this dynamic, seeking to better understand the impacts of the project on the urban mobility of the campus and the city in general.

\section{Space-time distribution of rides}

Since the system does not provide integrated mapping tools, geographic analysis is based on the selection of listed regions and text fields indicating the actual places people want to go, which makes it harder to process with accuracy. Regarding the data on rides, the major set of offered rides comprises a subset of concluded rides. A concluded ride is an offered ride that received at least one positive request and that request was accepted by the driver. Therefore, every completed ride is also an offered ride, but not every ride offered is necessarily completed. To date, more than 50,000 rides have been offered and 5,700 were completed, which makes for a rate of completion of approximately $12.5 \%$. Most of the analysis shown here will take into account only concluded rides.

As stated before, the platform indicates locations in Rio de Janeiro by neighbourhood names only (although more specific locative information can be added to the "notes" field of each ride), and cities names when dealing with the metropolitan area. To facilitate browsing the rides offered, neighbours and metropolitan area cities are grouped into zones, based on the division of the UFRJ 2020 Master Plan ("UFRJ 2020 Master Plan", 2011, p.34), which in its turn uses the official division of zones made by the administration of the city of Rio de Janeiro: North Zone, South Zone, Central Zone, West Zone, "Baixada" and "Niterói".

Regarding the distribution of ride offers in the areas of the city of Rio de Janeiro, the North Zone is 
Figure 4

Offered rides by city zone

Figure 5

Completed rides by city zone

Figure 6

Offered rides by university building

Figure 7

Completed rides by university building
OFFERED RIDES

$+50.000$
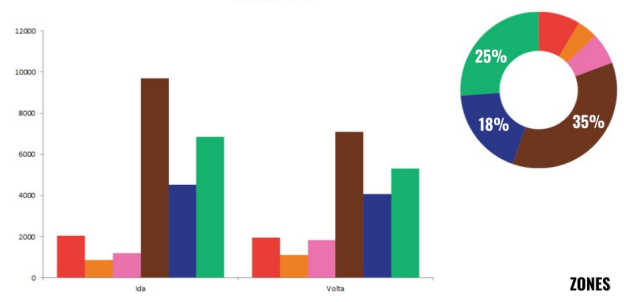

ZONES

\section{COMPLETED RIDES $\quad+\mathbf{5 . 7 0 0}$}

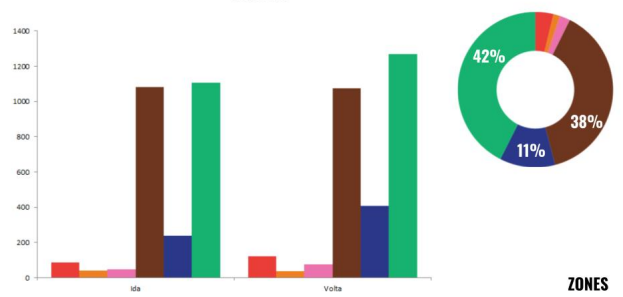

OFFERED RIDES

$+50.000$
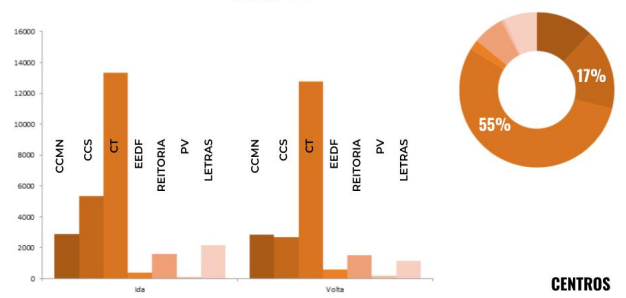

CENTROS

\section{COMPLETED RIDES \\ $+5.700$}

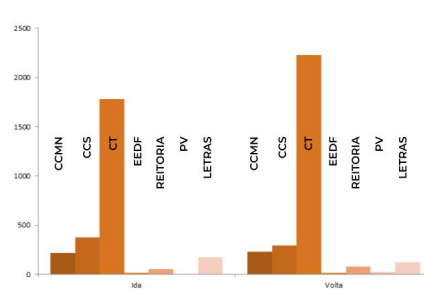

by far the one with the highest number of rides offered, totaling 16,778 , of which 9,690 are inbound and 7,088 are outbound. The South Zone comes next, with 12,149 rides offered in total, of which 6,844 are headed towards the University and 5,305 leaving it. This corresponds to the daily travel research presented in the Master Plan for the main campus, where the North Zone appears as the largest destination, followed by the South Zone. However, when it comes to the conclusion rate, the South Zone is the area of $\nabla$ the city that has the largest number of completed rides, 1107 inbound and 1229 outbound, 220 more than the North Zone, representing $19.5 \%$ of the rides against the $12.8 \%$ that account for the North Zone. So, the North Zone has the largest number of users and the highest number of rides offered, however, the South Zone has more rides effectively completed. In the number of rides offered, South Zone and West Zone are close, as in the number of users, but the conclusion rate is significantly lower for the West Zone.

In figures 4 and 5 we have the percentage distribution between the offered and completed rides, by city zones and university centers, also discriminated by inbound and outbound trips. It is interesting to note that the number of inbound trips is higher than outbound ones; but the number of completed rides tends to be approximately the same inbound or outbound, making outbound offers more likely to be completed for most of the city. This could be explained by the ease of organization of car rides within a relatively small area (when comparing to entire neighbourhoods) which is reinforced by the presence of the physical meeting points.

We can also observe the distribution for the different buildings of the campi Cidade Universitária and Praia Vermelha (figures 6, 7). The Technology Center ( $\mathrm{CT}$, home of Engineering Schools) is the the one that has more offered rides in and out, respectively 1,778 and 2,255 , also has the highest rate of conclusion, approximately $15.4 \%$ in the trip and $21 \%$ in the way back. Praia Vermelha, on the other hand, has fewer rides offered compared to $\mathrm{CT}$, but has a high rate of conclusion when outbound, reaching 
$15.7 \%$. As before, the total number of rides offered is higher when inbound, but when outbound the rate of conclusion is higher, perhaps because when inbound, drivers have more time to offer the ride in advance than when outbound, when it may be more difficult to predict the exact time of departure from the University.

The weekly distribution points out that the day of the week with the largest number of completed rides is Tuesday. Almost every day of the week has a greater number of outbound rides completed than inbound, with the exception of Friday and Saturday (but on Saturday only a few rides happened). Daily times of rides indicate an increase during peak traffic times in the city.

As for the number of riders (not including drivers) in each ride, more than half (3646) of the total number of completed rides (5930) has only one rider, and approximately $25 \%$ (1506) of rides happened with two riders; about $10 \%$ of the rides (618) had three riders; full rides, comprising four riders, represent only $2.7 \%$ of the total. This indicates that it is important to foster the increase of car occupation, to have more efficient trips. According to the project data, the average car occupancy rate is 2.53 inbound and 2.56 outbound. Compared to the average occupancy rate of cars in large Brazilian cities, the Caronaê system provides a significant increase of this rate, rationalizing the use of private cars.

\section{Network interactions: academic exchange in the UFRJ community}

In addition to the effects on urban mobility, rideshares promote meetings. In the specific case of Caronaê, usually the trip to the University campus takes at least 20 minutes, this means that for 20 minutes the participants of a ride will be together in a car. And participants usually have a common origin and destination, that is, they either live or perform some daily activity in the same region.

The networks arising from the rides registered in Caronaê were therefore analyzed by combining users and rides data tables. This made possible to answer some questions regarding the reiteration of users in the same rides : we started with how many times the same users were together in a ride, that is, how many trips had the same participants.

It was necessary to resort to SQL and Python programming to combine the main tables (users and rides), and the very design of a data structure for the intended Excel manipulation proved challenging, let alone programming the data transformation in Python. It is worth mentioning that this process was carried out jointly by the Caronaê team. Still, most of the analysis we wanted to do were not viable using regular spreadsheets, which lead to a query code (that took four hours to run) that resulted in the following results: in 3229 times, the same two users were together on a trip (which does not mean that they were the only participants in that trip). We used similar queries for times when three, four and five people were on the same trip, resulting respectively in 438,64 and 4 times. A curious outlier is the case of a full ride, with the same five people, that happened four times, which may indicate that the system might improve the formation of bonds through commuting after all, and lead to further investigation with other methods to support this initial findings.

Other questions arose, such as: how many trips had users of the same course?; or how many trips had travel with users of the same category in the University? And what those numbers represent in terms of the total number of rides? Further research will seek to improve the data extraction processes and the statistical tools in order to help us refine our questions and our answers. Are riders wanting more prone to take rides from the same course, or from the same category, or they tend to mix? Perhaps this is more common on the way back home, when people are concentrated in their respective buildings and, when inbound, it is more common that people are grouped by neighborhoods. Therefore, it is also important to know the number of trips with users with the same neighborhood of origin, revealing for example when people from close neighborhoods take rides, perhaps preferring to take a bus outside the campus in- 
stead of waiting more time for the right one there.

\section{CONCLUSION}

This paper brings a contribution to the discussion of the role of the location-based technologies and mobile devices in new - or renewed - possibilities for urban mobility. It also addresses a more specific concern with increasing opportunities of random creative exchange within a given community - one that congregates different skills but with a high degree of education. The paper is based on the assumption that those random encounters - in this case, while sharing rides - are part of a successful creative and innovative environment. We therefore study the dynamics of digitally mediated shared commuting in order to observe how different social and academic profiles mix are currently mixing - in contrast with other systems, even digitally mediated, where personal acquaintance - which tends to bring together those who think alike - is required.

Much is currently being discussed about the social implications of the massive use of information and communication technologies and of localization devices, especially regarding privacy issues, surveillance and population control. This is one of the keys to look at the subject, certainly a fundamental one. However, we argue here that we can also analyze - without losing sight of the critical aspects - other social dynamics that are mediated by mobile infocommunication devices and localization technologies, from the perspective of the potential of the expansion and diversification of encounters, in the case of Caronaê, those occurring during shared rides.

Even if at this point it is not possible to confirm if this actually happens, it is still important to analyze the Caronaê database in terms of demographics, riding habits and possible indications of groups mixing. The results show that further research in this direction, employing surveys and interviews, for instance, could prove fruitful,as well as the aforementioned refinement of data extraction and statistical analysis tools. On the other hand, the database itself could be improved if the University could made available a few more data about the users. One of the most striking examples is gender, which could help determine whether women give preference to female drivers and rides. Or date of entrance in the University, that could help visualize adoption and abandon of the system along time. But the Caraonaê database itself has room for improvement: even if it does not include real time location of users during rides, for instance, it could improve records of origin/destination of each ride, instead of recording only the information connected to the user profile. Caronaê, and the research involving it, also has to deal with sociocultural issues of adopting the specific platform visa-vis other common mobile apps such as Whatsapp of Facebook Messenger (which by their own nature cannot record accurate data about the rides), or more general ridesharing systems such as Wunder.

\section{ACKNOWLEDGEMENTS}

This study was financed in part by the Coordenação de Aperfeiçoamento de Pessoal de Nível Superior Brasil (CAPES) - Finance Code 001; and also by the Conselho Nacional de Desenvolvimento Científico e Tecnológico (CNPq), which provided the scholarship for the Master in Urbanism in PROURB/UFRJ. The authors would like to thank to their fellow colleagues at the Laboratory of Urban Analysis and Digital Representation - LAURD/PROURB for the contributions as well as the Graduate Program in Urbanism PROUR$B / U F R J$ for the support. We also would like to thank for the essential and generous collaboration of the Caronaê team and the University support.

\section{REFERENCES}

Balassiano, R, Andrade, AR and Santos, MP 2005, 'Gerenciamento da mobilidade: principios para a sua aplicação com base na informação', Revista Cetrama, 02

Borge-holthoefer, J, Rivero, A and Garcia, Inigo 2011, 'Structural And Dynamical Patterns On Online Social Networks: The Spanish May 15th Movement As A Case Study', Plos One, 6(8)

Calabrese, F, Colonna, M and Lovisolo, P 2011, 'Real-time Urban Monitoring Using Cell Phones: A Case Study In Rome', leee Transactions On Intelligent Transporta- 
tion Systems, 12(1), pp. 141-151

Calabrese, F and Ratti, C 2006, 'Real Time Rome', Networks And Communication Studies, 20(3-4), pp. 247-258

Netto, VM, Meirelles, JV, Pinheiro, M and Lorea, H 2018 , 'A temporal geography of encounters', CyberGeo, 2018(February)

de Souza e Silva, A 2013, 'Location-Aware Mobile Technologies: Historical, Social and Spatial Approaches', Mobile Media \\& Communication, 1(1), pp. 116-121

Teixeira, LdC 2019, Plataformas digitais de mobilidade urbana : o caso do Caronae UFRJ, Master's Thesis, Universidade Federal do Rio de Janeiro

Teixeira, LdC, Meyer, MDF, Damasceno, RG and Balassiano, R 2018 'Caronae: gerenciamento da mobilidade urbana na UFRJ', XVI Rio de Transportes, Rio de Janeiro, pp. 291-302

Teixeira, LdC and Paraizo, RC 2018 'Digital Platforms for urban mobility', SIGraDi 2018 Tecnopoliticas, São Carlos, pp. 957-964

[1] http://redpgv.coppe.ufrj.br/index.php/pt-BR/concei

tos/o-que-e-um-pgv 